\title{
Pregnancy and Protection: The Ethics of Limiting a Pregnant Woman's Participation in Clinical Trials
}

\author{
Lori Allesee $^{1}$ and Colleen M. Gallagher ${ }^{2 *}$
}

${ }^{1}$ Bioethics Research Intern, Saint Mary's University, USA

${ }^{2}$ Chief \& Executive Director, Integrated Ethics in Cancer Care, Associate Professor, Critical Care, The University of Texas M.D. Anderson Cancer Center, USA

\begin{abstract}
The call for the inclusion of pregnant women in clinical trials has received renewed attention recently. This interest springs from articles in various medical journals highlighting the gaps in medical knowledge and the need to improve health care for pregnant women.
\end{abstract}

It is not a simple decision whether to include pregnant women in studies or not. The general thought is that it's too dangerous for the baby if a pregnant woman is participating in a trial, and the absence of research on how medications work in pregnant women leave doctors guessing about how to safely and effectively treat patients through pregnancy.

Excluding pregnant women from clinical trials are not automatic, not unethical nor is it arbitrarily determined. The regulatory framework is based on sound ethical and legal reasoning that demonstrates when inclusion in a clinical trial is appropriate or when clear and compelling reasons for exclusion are presented.

Learning objective: Readers will learn about limitations of research, history of the inclusion and exclusion of pregnant women in clinical trials, reticence for inclusions, as well as regulations designed using reasoned legal and ethical principles, such as: Principle of Autonomy, Informed Consent, and Beneficence and Nonmaleficence.

Keywords: Ethics of limiting a woman's participation in clinical trials; Pregnancy and protection; Woman's participation in clinical trials; Treating pregnant women; inclusion of pregnant women in clinical trials; Exclusion of pregnant women in clinical trials

\section{Introduction}

The call for the inclusion of pregnant women in clinical trials has received renewed attention recently. This interest springs from articles in various medical journals highlighting the gaps in medical knowledge and the need to improve health care for pregnant women [1-4]. For instance, research shows that a healthy woman's pregnancy is most commonly complicated by psychiatric illness, hypertension, and cancer. Sixty-four percent of pregnant women will be given at least one prescription for medical needs [1-4]. Yet, safe and effective treatments for these illnesses are empirical, not evidence based, due to well-documented barriers to inclusion in experimental studies [3]. Presumably a reduction in these barriers would yield an evidencebased understanding of the physiological effects of drugs on pregnant women, but hanging in the balance are the unknown harms to the fetus, as well as liability to manufacturers with detrimental consequences to current beneficiaries of clinical trials.

A reduction in the aforementioned barriers would be problematic. Excluding pregnant women from clinical trials is not automatic, not unethical nor is it arbitrarily determined [5]. The regulatory framework is based on sound ethical and legal reasoning that demonstrates when inclusion in a clinical trial is appropriate and when clear and compelling reasons for exclusion are presented [5].

In developing an ethical framework for the protection of human subjects, the Department of Health and Human Services applied the findings of The Belmont Report [5]. Broadly speaking, the ethical principles utilized in the Report are: 1) autonomy, 2) beneficence, 3) non-maleficence, and 4) justice [6]. Even before the Commission's use of this report, this analytical framework achieved general acceptance in clinical and research medicine as a sound method for ethical decisionmaking [7]. In 1976 these principles framed the language of the
Protection of Human Subjects regulations (hereafter referred to as "the regulations"), and on balance 35 years later, these regulations remain reliably protective of pregnant women and their unborn children, manufacturers and greater society.

\section{Limitation of this research}

Examining the ethics of the exclusion or inclusion of pregnant women in clinical trials requires an analysis of the federal regulations for the protection of human subject research. As such, this research addresses the applicable passages of the Code of Federal Regulations -- Title 45, Part 46, the Regulations of the Department of Health and Human Services, and Title 21 those of the Food and Drug Administration [6].

Several limitations of this research should be noted. First, this research assumes the following: The pregnant woman and her unborn child are healthy, the pregnant woman wants her child, the fetus has reached the point of viability, and the pregnant woman is starting a drug therapy, not continuing a drug therapy.

Second, the regulatory definition of viability is used. Viability, as defined by the Code of Federal Regulations, is not a determination of the philosophical understanding of personhood, rather it pertains

${ }^{*}$ Corresponding author: Colleen Gallagher, Chief and Executive Director, Section of Integrated Ethics, Associate Professor, Department of Critical Care, Co-Director, Bioethics Initiative for Equity in Health Care and Research, The University of Texas M.D. Anderson Cancer Center, USA, Tel: 713-792-2857; Fax: 713-745-0674; E-mail: CMGallagher@mdanderson.org

Received October 13, 2010; Accepted March 30, 2011; Published March 31, 2011

Citation: Allesee L, Gallagher CM (2011) Pregnancy and Protection: The Ethics of Limiting a Pregnant Woman's Participation in Clinical Trials. J Clinic Res Bioeth 2:108. doi:10.4172/2155-9627.1000108

Copyright: (C 2011 Allesee L, et al. This is an open-access article distributed under the terms of the Creative Commons Attribution License, which permits unrestricted use, distribution, and reproduction in any medium, provided the original author and source are credited. 
to the ability of a neonate to survive to the point of independently maintaining a heartbeat and respiration [7].

Lastly, this analysis limits examination of justice to the theory of distributive justice. Although all theories of justice are relevant to research involving human subjects, the concept of justice most widely applied in the foundational study The Belmont Report and to health care in general is that of distributive justice.

\section{History of the Inclusion and Exclusion of Pregnant Women in Clinical Trials}

In response to abuses in medical research, the United States government created the National Research Act [8]. This act requires Institutional Review Boards - members whose charge it is to protect the rights and welfare of research participants - approve all studies involving human subjects [8]. It also created the National Commission for the Protection of Human Subjects of Biomedical and Behavior Research [8]. The Commission produced the Belmont Report which drafted a foundational document for the ethics of human subject research in the United States [10]. Identified and summarized were the following basic principles which underlie the ethical conduct of biomedical research: 1) respect for persons, 2) beneficence and non-maleficence, and 3) justice [9]. These principles were not intended to exclude, or for that matter include, women from clinical trial participation [9]. Instead, they were drafted as a guide to assure that research involving human subjects is carried out in an ethical manner [9].

Today, this construct continues to raise questions about the appropriateness of the inclusion of pregnant women in clinical trials. At issue, of course, is the balance of risks and benefits to the fetus.

\section{Reticence for Inclusion}

\section{Drug manufacturers reticence}

Reticence by the drug manufacturers is founded on two historical tragedies. The financial aftermaths of the diethylstilbestrol (commonly referred to as DES) and thalidomide lawsuits caused many drug manufacturers to react by being unreceptive to women into their clinical trials [10].

DES was used from 1938 to 1971 to prevent miscarriage. An estimated 1.5 million to 3 million women were prescribed the drug during pregnancy. It was later realized that this drug did not prevent miscarriage [10]. And, over time it was linked to cancer in the daughters of the treated women [10].

In 1980, the California Supreme Court decided a landmark case, Sindell v. Abbott Laboratories [10]. This class action, brought by Judith Sindell, was seeking redress for injuries resulting from DES drug exposure before birth. Numerous drug manufacturers produced DES. This court reduced the plaintiff's burden of proof and modified traditional tort doctrine by apportioning damages between defendants by market share. The Sindell Court ruled: "As between an innocent plaintiff and negligent defendants, the latter should bear the cost of the injury" [10]

DES litigation had a widespread impact on pharmaceutical companies. For instance, as of 1979, Eli Lilly was subject to lawsuits totaling between $\$ 3$ and $\$ 4$ billion [11]. By 1982, the company spent an estimated $\$ 5$ to $\$ 6$ million on defense [10]. Yet Eli Lilly's total market share of sales of DES from 1947 to 1971 was estimated at \$2.5 million. [11] Obviously, the financial impact of this outcome was staggering.

Meanwhile, another drug tragedy occurred. Throughout the late 1950s and 1960s, thalidomide was being administered to impart drowsiness, and later it was used to treat morning sickness in pregnant women [12]. However, soon after being prescribed to pregnant women, thalidomide was linked to debilitating birth defects in more than 8,000 newborns and another 7,000 died of their deformities before birth [12].

Like the manufactures of DES, Grunenthal, the maker of thalidomide, confronted similar problems: a growing number of complaints and lawsuits [12]. Although the United States escaped the effects of this tragedy because the drug was never approved by the FDA, the implications for pharmaceutical manufacturers worldwide are clear [12].

Despite these cases having occurred more than 40 years ago, drug manufacturers remain cautious about the inclusion of pregnant women due to fear of liability based on the potential harm to the fetus [13]. Some might argue that the worries about legal responsibility are even more valid today than before. Today, evidence of a teratogenic drug which causes a birth defect can trigger negligence claims. While a person can waive liability for themselves, a parent cannot waive causes of action on behalf of their children. Causing additional anxiety is the recognition that most jurisdictions allow tort actions for prenatal injuries if the child is subsequently born alive [14]. Further, a third generation of litigation has begun involving DES grandchildren [15].

\section{Institutional review board reticence}

Liability is also a consideration for Institutional Review Boards (IRBs) and a handful of recent cases have validated this concern [16]. Charged with protecting the rights and welfare of human subjects participating in clinical trials, the IRB has the directive to ensure that research participants are properly informed of the risks in clinical trials [17]. Although they are few, cases exist in which there were injuries to unborn children, and the inadequacy of warning or the lack of informed consent was an essential element of the lawsuit against the IRB [18]. Of greater concern to IRB members, however, is the inherent and unknown danger to the fetus [19]. As the reasoning below explains and the DES and thalidomide tragedies demonstrate, there are serious consequences for the pregnant woman, fetus, researcher, and drug manufacturer.

\section{Regulations rest on reasoned legal and ethical principles}

It is important to note the regulations protecting human subjects are not a full prohibition of the inclusion of pregnant women in clinical trials [17]. Instead, the regulations construct criteria for IRB members to utilize in formulating basic requirements of ethical decision-making [17].

\section{Principle of autonomy}

The first fundamental concept is respect for patients' autonomous decision making. The ethical principle of autonomy and the common law both respect and recognize a patient's right to self-determination. In both disciplines the principle is applied through the use of informed consent.

Autonomy, however, is not without limits. Ethics and the law recognize that it is permissible to place restrictions on one's autonomy especially in instances where personal autonomy infringes on the rights of others [20]. For example, autonomy in the relationship between the mother and the fetus presents challenging questions. The relationship between and pregnant woman is complex and inexorably linked, as Illinois Supreme Court Justice Cunningham detailed in Stallman v. Youngquist:

The relationship between a pregnant woman and her fetus is unlike 
the relationship between any other plaintiff and defendant. No other plaintiff depends exclusively on any other defendant for everything necessary for life itself. No other defendant must go through biological changes of the most profound type, possibly at the risk of her own life, in order to bring forth an adversary into the world. It is, after all, the whole life of the pregnant woman which impacts on the development of the fetus. As opposed to the third-party defendant, it is he mother's every waking and sleeping moment which forms the world for the developing fetus. This is not a pregnant woman's fault: It is a fact of life [21].

This expression is further carried out in Health and Human Services' Institutional Review Board Guidebook. As explained, the regulations on pregnant women are a direct recognition of the vulnerability of fetus and instruct IRB members to treat the fetus with dignity and respect [22].

Respect for the fetus does not come at the expense to the pregnant woman's autonomy. The rationale rather is that the interest in protecting fetuses is achieved only by helping pregnant women make informed, less constrained choices. Through informed consent, IRB members realize respect for a woman's autonomy and recognize the freedom of women to exercise their judgments in order to act for their own interest.

\section{Informed consent}

Informed consent takes on different meanings in the courts and in research ethics. In the law, informed consent is generally a duty imposed on the physician to properly disclose the significant risks incidental to a treatment [23]. Consider for example the holding in Shack v. Holland:

Conditional prospective liability to fetus is created when an unborn child's mother is not sufficiently informed of risks, hazards and alternatives of delivery procedure administered, and such liability attaches upon birth of child and insures to benefit of child as cause of action for lack of informed consent [24].

On the other hand, in ethics, the scope of informed consent is broadened to include shared decision-making. Biomedical ethicists Tom L. Beauchamp and James F. Childress explain informed consent and shared decision-making are not mutually exclusive. Informed consent, in this context, is an exchange of information between the physician and the patient which leads to an agreed upon plan of medical care [25]. The difference, as explained by Albert J. Jonsen, Mark Siegler and William Winslade, is simply:

Informed consent is not merely pushing information at a patient. It is an opportunity to initiate a dialogue between physicians and their patients in which both attempt to arrive at a mutually satisfactory course of action. Informed consent should result in shared decision making. The process, although difficult, is not impossible and is always open to improvement [26].

In developing the regulatory framework for research involving pregnant women and their fetuses, the Commission utilized the higher, ethical standard and broke down informed consent into three elements: information, comprehension and voluntariness [27]. Clearly, neonates cannot meet any of these three elements. Generally, in law and in ethics, parents are generally recognized as having the right and responsibility make health care decisions in the child's best interest [28]. With that in mind, section 46.204(f) sets out the limitation:

Each individual providing consent under paragraph (d) or (e) of this section is fully informed regarding the reasonably foreseeable impact of the research on the fetus or neonate [20].
Of course, many factors interfere with the expression and appreciation of the patient's preference, especially when considering what is owed to fetuses when involved in research that holds no promise of a direct benefit to them or to the pregnant woman. Medical researchers recognize that clinical trials are for the betterment of generalizable knowledge, not for access to better medical care for oneself. It is an ultimate sacrifice. The pertinent sections of the regulation - Sections 46.204 - which balances harms and benefits- are discussed in more detail in the following section.

\section{Beneficence and nonmaleficence}

Maternal-fetal patient relationships are complex. The principle of beneficence and its counterpart, non-maleficence, require the physician to objectively assess therapeutic options and implement those that will most offer the patient the greatest balance of benefit over risk [30].

Under the limitations of this research, the physician can have beneficence and non-maleficence-based obligations toward both the pregnant woman and the fetus.

In the law there is clear guidance for when a duty is imposed on the physician. In Texas, the general rule holds that: "Provided it is subsequently born alive, even an unborn fetus, is a "patient" to whom a doctor treating the mother owes a duty" [31]. Similar conclusions have been reached in other jurisdictions. Consider a New Jersey decision which declared: "It is settled law that a doctor's duty to a pregnant woman extends to a child born of that pregnancy" [31].

Ethicists Frank Cherenak reaches a similar conclusion in determining when an ethical duty should be imposed. He suggests that ethical obligations are owed to the infant, which a fetus will become upon its birth. Using this reasoning, the fetus is a patient, regardless of whether it is a person [32]. By extension these obligations apply to the viable fetus [32]. Thus, the comparing of benefits and risks applies to both the fetus and the pregnant woman. Should a pregnant woman's decisions conflict with the best interest of the fetus, then the physician has an obligation to effect protection of both parties' interests [32].

Beneficence and nonmaleficence require researchers and IRB members to weigh the potential risks versus benefits of any proposed study with an eye toward maximization of benefits and minimization of risks to all study participants. The Belmont Reports echoes the value of a systematic assessment of risks and benefits suggesting that when vulnerable populations are involved, the appropriateness of their inclusion should be assessed [33]. This assessment should include the nature and the degree of the risk and the nature and level of the anticipated benefit [34].

Together, these theories provide the basis for the general limitations on this protected population. First, the regulation asks IRB members to consider inclusion after previous research has been performed.

Where scientifically appropriate, preclinical studies, including studies on pregnant animals, and clinical studies, including studies on non-pregnant women, have been conducted and provide data for assessing potential risks to pregnant women and fetuses [35].

Second, inclusion may then be considered with the proper informed consent of the woman.

If the research holds out the prospect of direct benefit to the pregnant woman, the prospect of a direct benefit both to the pregnant woman and the fetus, or no prospect of benefit for the woman nor the fetus when risk to the fetus is not greater than minimal and the purpose of the research is the development of important biomedical knowledge 
that cannot be obtained by any other means her consent is obtained in accord with the informed consent provision of subpart $\mathrm{A}$ of this part [36].

Third, inclusion may then be considered if there is possible direct benefit solely to the fetus and with the consent by both parents.

If the research holds out the prospect of direct benefit solely to the fetus then the consent of the pregnant woman and the father is obtained in accord with the informed consent provisions of Subpart A of this part, except that the father's consent need not be obtained if he is unable to consent because of unavailability, incompetence or temporary incapacity or the pregnancy resulted from rape or incest [35].

Finally, inclusion can then be triggered when either the prospect of direct benefit to a woman or fetus, or risk is no greater than minimal.

The risk to the fetus is caused solely by interventions or procedures that hold out the prospect of direct benefit for the women or the fetus; or, if there is no such prospect of benefit, the risk to the fetus is not greater than minimal and the purpose of then research is the development of important biomedical knowledge which cannot be obtained by any other means [20].

A thorough interpretation of this rule then is evidence that the ethical principles of beneficence and non-maleficence already contemplate the inclusion of pregnant women in clinic trials. This is a clear argument against the broadening of the regulations. Stated more directly: "In the case of scientific research in general, members of the larger society are obligated to recognize the longer term benefits and risks that may result from the improvement of knowledge and from the development of novel medical, psychotherapeutic, and social procedures".

\section{Justice}

Some argue that the issue of inclusion and exclusion of pregnant women in clinical trials turns on the element of justice. That is, to whom what is owed? But because medical research continues to be a limited resource, this principle must be more far-sighted and look not only to who should benefit, but also who should bear the burden. This approach is a form of distributive justice. Simply stated, this principle requires that distribution of goods and services, including access to clinical trials are fair. Of the concepts of fairness, the traditional notion of distributive justice is most widely relied upon in medical research [35].

Beauchamp and Childress state that determination of a fair distribution involves a evaluation of the following factors: to each person an equal share, to each person according to need, to each person according to effort, to each person according to contribution, to each person according to merit, or to each person according to freemarket exchanges [35]. When using these factors to justify inclusion of pregnant women in clinical trials, however, a tension is created due to scarce resources, the need for liability protections for manufacturers and protection of those currently benefitting from clinical trials. The underlying dilemma is further complicated by the fact that the principle of distributive justice does not determine what a health need is or which or whose needs are more important.

As the Belmont Report http://ohsr.od.nih.gov/guidelines/belmont. html (last accessed on April 15th, 2011) advised and the regulations support, medical research on any given group should not unduly affect persons from other groups unlikely to be among the beneficiaries of the subsequent applications of research [5]. Proponents of inclusion argue that justice for a given group (pregnant women) might demand inclusion, but a win on this argument would come at the expense of justice for another group (the pharmaceutical companies). There is a growing body of evidence supporting the contentions that research is needed to ensure the safety and efficacy of treatment plans for both the woman and her fetus, that foregoing treatment could raise serious health implications, and that direct benefits are sometimes denied to a pregnant woman. However, a more liberal regulation might disproportionately affect members of other groups, namely fetuses, pharmaceutical companies, current research subjects and consumers, particularly the less educated and less wealthy [35].

Economic considerations in the allocation of resources cannot be ignored when considering inclusion. First, there is the high cost that is associated with clinical trials, and there is a small market in pregnant women. By the Division of Vital Statistics estimates in the year 2000, 6,401,000 pregnancies resulted in 4.06 million live births [36]. Of those, 400,000 were women confronting medical illnesses while pregnant, a minority of pregnant women, albeit a significant minority. Pharmaceutical companies report that on average they invest between $\$ 100$ million and $\$ 800$ million per drug candidate [37].

Second, American health care jurisprudence creates a perceived risk of excessive legal liability from toxicity to fetuses, and creates companies that are risk averse. To put matters into perspective, in 2002, pharmaceutical companies paid more than $\$ 24$ billion in malpractice payments; these rulings leave companies with no option but to be risk adverse [38]. In addition, these awards tend to stifle the research drive necessary to create new and beneficial drugs, while the damages are absorbed by consumers, particularly the less educated and less wealthy, who are the greatest consumers of pharmaceuticals [38].

\section{Conclusion}

The regulations which limit a pregnant woman from clinical trials are not automatic, not unethical nor arbitrarily determined. Instead, the rules merely set out a framework to guide IRB members to determine when inclusion is appropriate and when compelling reasons for exclusion are presented. Further, the regulations are reasoned in both ethics and law and demonstrate a balance of respect and dignity for patients, the pregnant woman and her fetus.

\section{Funding}

This initiative is supported by the National Institutes of Health, contract \#1 RC2 MD004764-01.

\section{References}

1. Donald Mattison, Anne Zajicek (2006) CSD Grand Rounds: Gaps in Knowledge in Treating Pregnant Women. Gender Medicine 3: 169-182.

2. Francoise Baylis (2010) Pregnant Women Deserve Better. Nature 465: 689 690

3. Lyerly AD, Little MO, Faden RR (2008) "Pregnancy and Clinical Research Hastings Cent Rep 38.

4. Ruth Macklin (2010) The Art of Medicine: Enrolling Pregnant Women in Biomedical Research. The Lancet 375: 632-633.

5. The Belmont Report: Ethical Principles and Guidelines for the Protection of Human Subjects of Research. (2010).

6. Jonsen A, Siegler M, Winslade WJ (2006) Clinical Ethics: A Practical Approach to Ethical Decisions. Clinical Medicine 2-10 (McGraw-Hill 6 ${ }^{\text {th }}$ ed.).

7. Protection of Human Subjects, 45 C.F.R. $\$ 46.202$ (2010). "Viable, as it pertains to the neonate, means being able, after delivery, to survive (given the benefit of available medical therapy) to the point of independently maintaining heartbea and respiration." The definition further provides that where the neonate is 
Citation: Allesee L, Gallagher CM (2011) Pregnancy and Protection: The Ethics of Limiting a Pregnant Woman's Participation in Clinical Trials. J Clinic Res Bioeth 2:108. doi:10.4172/2155-9627.1000108

Page 5 of 5

viable then it may be included in research in accordance with the basic policy protections for human research subjects and the policy of additional protections for children involved as subjects in research.

8. National Research Act of 1974, Publ. L. No. 93-348 (codified as amended at 45 C.F.R $\S 46(2010))$.

9. The Belmont Report: Ethical Principles and Guidelines for the Protection of Human Subjects of Research.

10. Sindell v. Abbott Laboratories, 607 P.2d 924 (Cal. 1980). Under the theory of enterprise liability, women brought a class action against drug manufacturers to recover from injuries they sustained as a result of administration of DES to their mothers during pregnancy.

11. DES Revenge, Mother Jones, 34-42 (February/March 1983).

12. Philip J. Hilts, The FDA at Work - Cutting Edge Science Promoting Public Health, FDA Consumer Magazine (January - February 2006).

13. R. Alta Charo (1993-1994) Protecting Us To Death: Women, Pregnancy and Clinical Research Trials, 38 St. Louis U. L.J. 135.

14. Restatement (Second) of Torts $\S 869$ (2010)

15. Paul Marcotte, DES Legacy, 14 (June 1990).

16. Areta L. Kupchyk and Josephine M. Torrente, Pharmaceutical Law 2006 Across the Product Life Cycle, R\&D 101: Legal Issues During Research and Development, Practising Law Institute: Patents, Copyrights, Trademarks, and Literary Property Course Handbook Series (October 4-6).

17. Protection of Human Subjects, 45 C.F.R. $\S 46$

18. See Areta L. Kupchyk and Josephine M. Torrente, Pharmaceutical Law 2006 : Across the Product Life Cycle, R\&D 101: Legal Issues During Research and Development, Practising Law Institute: Patents, Copyrights, Trademarks, and Literary Property Course Handbook Series (October 4-6).

19. See Jacqulyn Kay Hall, Exclusion of Pregnant Women from Research Protocols: Unethical and Illegal, 17 IRB Human Subjects Research 1-3 (MarchApril 1995).

20. Albert R. Jonsen (2005) Bioethics Beyond the Headlines: Who Lives, Who Dies, Who Decides, 154-159, Rowman \& Littlefield, Publishers, Inc.

21. Stallman v. Youngquist, 531 N.E.2d 355, 360 (III. 1998) (holding that there is no cause of action by or on behalf of a fetus, subsequently born alive, against its mother for the unintentional infliction or prenatal injuries)

22. Institutional Review Board Guidebook, Chapter VI: Special Classes of Subjects at http://www.hhs.gov/ohrp/irb/irb.chapter6.htm\#g2 (last accessed on August 12, 2010). The Guidebook is clear to note that the Commission for the Protection of Human Subjects did not attempt to define person, but acknowledged that respect and dignity for the fetus should be expressed regardless of the viability of the fetus.

23. Wagner v. Georgetown University Medical Center, 768 A.2d 546, 561 (D.C 2001) (holding that in an informed consent claim, a causal connect exists when, disclosure of significant risks incidental to treatment would have resulted in a decision against it)

24. Shack v. Holland, 389 N.Y.S. 2 d 988 (Sup. Ct. 1976)

25. Tom L. Beauchamp and James F. Childress, Principles of Bioethics, $6^{\text {th }}$ edition, New York, Oxford Press 99-122 (2009).

26. Albert J. Jonsen, Mark Siegeler and William J. Winslade, Clinical Ethics: A Practical Appraoch to Ethical Decisions in Clinical Medicine 18-38, 6 th edition, McGraw Hill Medical Publishing Edition (2006)

27. http//ohsr.od.nih.gov/guidelines/belmont.html (last accessed on August 9 2010).

28. Canesi ex rel. Canesi v. Wilson, 730 A.2d. 805, 811(N.J. 1999)(reasoning that because a parent's protectable interest is the personal right of selfdetermination, a physician's duty to disclose must be sufficient to enable her to make a meaning decisions).

29. Tom L. Beauchamp and James F. Childress, Principles of Bioethics, $6^{\text {th }}$ edition New York, Oxford Press 149-152 (2009).

30. HCA, Inc. v. Miller, 36 S.W.3d 187 (Tex. App. Houston [14 ${ }^{\text {th }}$ Dist.] 2000, aff'd, 118 S.W.3d 758 (Tex. 2003).

31. Lynch v. Scheininger, 714 A.2d 970 (NJ Appellate 1998) (reaffirming Procanik v. Cillo, 478 A2d 755 (1984).

32. Frank N. Chevenak et al., Ethical Issues In the Management of Pregnancies Complicated by Fetal Anomalies, 7 Obsterical and Gynecological Survey 473483 (2003).

33. http//ohsr.od.nih.gov/guidelines/belmont.html (last accessed on March 10 2011).

34. Tom L. Beauchamp and James F. Childress, Principles of Bioethics, $5^{\text {th }}$ edition, New York, Oxford Press (2001).

35. Chen Sen WU (2006) Distributive Justice in Pharmaceutical Torts: Justice Where Justice is Deserved, 69 Law and Contemporary Problems 207.

36. Stephanie J. Venture, et al. Estimated Pregnancy Rates for the United States 1990-2000: An Update. 52:23 (June 15, 2004).

37. Robert Fee (2007) The Cost of Clinical Trials, 10 Drug Discovery and Development Magazine 32 (March 2007)

38. Chen Sen Wu (2006) Distributive Justice in Pharmaceutical Torts: Justice Where Justice is Deserved, 69 Law and Contemporary Problems 207. 